\title{
Small Intestine Cancer cM1 TNM Finding v8
}

National Cancer Institute

\section{Source}

National Cancer Institute. Small Intestine Cancer CM1 TNM Finding v8. NCI Thesaurus.

Code C133829.

Small intestine cancer with distant metastasis. (from AJCC 8th Ed.) 